\title{
Trends in intensity-modulated radiation therapy use for rectal cancer in the neoadjuvant setting: a National Cancer Database analysis
}

\author{
Rodney E. Wegner, MD, Stephen Abel, DO, Richard J. White, DO, Zachary D. Horne, MD, \\ Shaakir Hasan, DO, Alexander V. Kirichenko, MD, PhD \\ Division of Radiation Oncology, Allegheny Health Network Cancer Institute, Pittsburgh, PA, USA
}

\begin{abstract}
Purpose: Traditionally, three-dimensional conformal radiation therapy (3D-CRT) is used for neoadjuvant chemoradiation in locally advanced rectal cancer. Intensity-modulated radiation therapy (IMRT) was later developed for more conformal dose distribution, with the potential for reduced toxicity across many disease sites. We sought to use the National Cancer Database (NCDB) to examine trends and predictors for IMRT use in rectal cancer.

Materials and Methods: We queried the NCDB from 2004 to 2015 for patients with rectal adenocarcinoma treated with neoadjuvant concurrent chemoradiation to standard doses followed by surgical resection. Odds ratios were used to determine predictors of IMRT use. Univariable and multivariable Cox regressions were used to determine potential predictors of overall survival (OS). Propensity matching was used to account for any indication bias.

Results: Among 21,490 eligible patients, 3,131 were treated with IMRT. IMRT use increased from 1\% in 2004 to 22\% in 2014. Predictors for IMRT use included increased N stage, higher comorbidity score, more recent year, treatment at an academic facility, increased income, and higher educational level. On propensity-adjusted, multivariable analysis, male gender, increased distance to facility, higher comorbidity score, IMRT technique, government insurance, African-American race, and non-metro location were predictive of worse OS. Of note, the complete response rate at time of surgery was 28\% with non-IMRT and 21\% with IMRT.

Conclusion: IMRT use has steadily increased in the treatment of rectal cancer, but still remains only a fraction of overall treatment technique, more often reserved for higher disease burden.
\end{abstract}

Keywords: Intensity-modulated radiotherapy, IMRT, Rectal cancer, Radiotherapy, National Cancer Database (NCDB)

\section{Introduction}

Rectal cancer continues to be a relatively common malignancy across the United States, being diagnosed in close to 50,000 patients each year [1]. The standard of care treatment approach is neoadjuvant chemoradiation followed by surgery for the vast majority of locally advanced cases based on strong randomized data $[2,3]$. Recent publications using the National Cancer Database (NCDB) have confirmed an increase in the use of this neoadjuvant approach [4]. Classically threedimensional conformal radiation therapy (3D-CRT) has been used which utilizes CT imaging, bony landmarks, but also

Received 18 October 2018, Revised 30 October 2018, Accepted 01 November 2018.

Correspondence: Rodney E. Wegner, MD, Division of Radiation Oncology, Allegheny Health Network Cancer Institute, 320 E. North Ave, Pittsburgh, PA 15212, USA. Tel: +1-412-359-3400, Fax: +1-412-359-3171, E-mail: Rodney.wegner@ahn.org (http:// orcid.org/0000-0003-2416-3499)

(c) This is an Open Access article distributed under the terms of the Creative Commons Attribution Non-Commercial License (http://creativecommons.org/ licenses/by-nc/4.0/) which permits unrestricted non-commercial use, distribution, and reproduction in any medium, provided the original work is properly cited.

www.e-roj.org 
contoured targets and critical structures to develop a radiation plan. Intensity-modulated radiation therapy (IMRT) is a more technically advanced way to deliver radiation, allowing for more conformality, sparing of surrounding critical structures, and potentially decreased toxicity [5]. The use of pelvic IMRT sky rocketed appropriately in anal cancer with an obvious and expected benefit of decreased toxicity seen in RTOG 0529 $[6,7]$. With regards to rectal cancer, low lying lesions are often treated similar to anal canal cancers based on patterns of lymphatic drainage [8]. In addition, mid and distally located rectal lesions may still benefit from IMRT due to decreased dose to the small bowel [9-11]. With those points in mind, it stands to reason that IMRT is likely being utilized more frequently in rectal cancer. As such, we sought to use the NCDB to examine trends and predictors for IMRT use in rectal cancer in the preoperative setting.

\section{Materials and Methods}

The logistics and methods for analyzing the NCDB have been described previously $[12,13]$. We conducted a retrospective review using de-identified data from the NCDB, which is exempt from the Institutional Review Board oversight. The NCDB is a tumor registry jointly maintained by the American Cancer Society and the American College of Surgeons for more than 1,500 hospitals accredited across the United States by the Commission on Cancer. The database is estimated to capture up to 70\% of newly diagnosed malignancies each year across the country. We queried the database for patients with the American Joint Committee on Cancer (AJCC) clinical stage 2-3 rectal adenocarcinoma (ICD-0-3 histology codes 8140 , 8210, 8260-63, 8470, 8480, and 8481) diagnosed between 2004 and 2015. As IMRT use was a recorded NCDB parameter, patients treated with IMRT were identified and compared to those receiving a non-IMRT based radiation technique. We excluded patients with stage I and IV disease, undocumented stage, no neoadjuvant treatment, non-pelvic radiation therapy, and non-neoadjuvant radiation dose (defined as < 45 Gy and $>73 \mathrm{~Gy}$ ). We used a cutoff of $73 \mathrm{~Gy}$ to exclude patients that clearly had errors in documentation of their total radiation dose. To that end, $<1 \%$ of patients received a dose $>60 \mathrm{~Gy}$. In addition, we excluded patients that were not treated with concurrent systemic therapy or those patients with less than 2 months of follow-up to account for immortal time bias. Fig. 1 is a CONSORT diagram further outlining the cohort selection criteria.

Race was broken down into three broad categories:
Caucasian, African-American, or other. Comorbidity was quantified using the Charlson/Deyo comorbidity index [14]. Stage was defined according to the 7th edition of the AJCC clinical group. Socioeconomic data in the patients' residence census tract were provided as quartiles of the percentage of persons with less than a high school education and median household income. The facility type was assigned according to the Commission on Cancer accreditation category. Locations were assigned based on data provided by the US Department of Agriculture Economic Research Service. Insurance status is documented in the NCDB as it appears on the admission page. The data used in the study are derived from a deidentified NCDB file. The American College of Surgeons and the Commission on Cancer have not verified and are not responsible for the analytic or statistical methodology employed, or the conclusions drawn from these data by the investigator.

Data were analyzed using MedCalc Statistical Software version 18 (MedCalc Software, Ostend, Belgium). Summary statistics are presented for discrete variables. Chi-square tests compared sociodemographic, treatment, and tumor characteristics between the treatment groups. Overall survival was calculated in months from time of diagnosis to date of last contact or death which is recorded in the NCDB. KaplanMeier curves were used to calculate cumulative probability of survival [15]. Log-rank statistics were used to test whether there was a statistically significant difference in the cumulative proportions across groups. A Cox proportional hazards model was used for multivariable survival analysis [16]. Due to the large nature of the dataset, factors were entered using a stepwise backward elimination process. Adjusted hazard ratios and $95 \%$ confidence intervals are reported, using a p-level of 0.05 to indicate statistical significance.

Propensity score-adjusted survival analysis was used to account for indication bias due to lack of randomization between patients receiving 3D-CRT and IMRT [17]. Multivariable logistic regression was used to calculate a propensity score indicative of conditional probability of receiving conventional 3D-CRT or IMRT. The propensity model included observable variables associated with treatment selection on multivariable logistic regression. A Cox proportional hazards model was then constructed incorporating the propensity score, but also excluding factors included in the propensity score calculation to avoid overcorrection. The assumption of balance was further validated by stratifying the data into propensity score-based quintiles, and confirming that the difference in propensity score mean per quintile was less than 0.10 . 


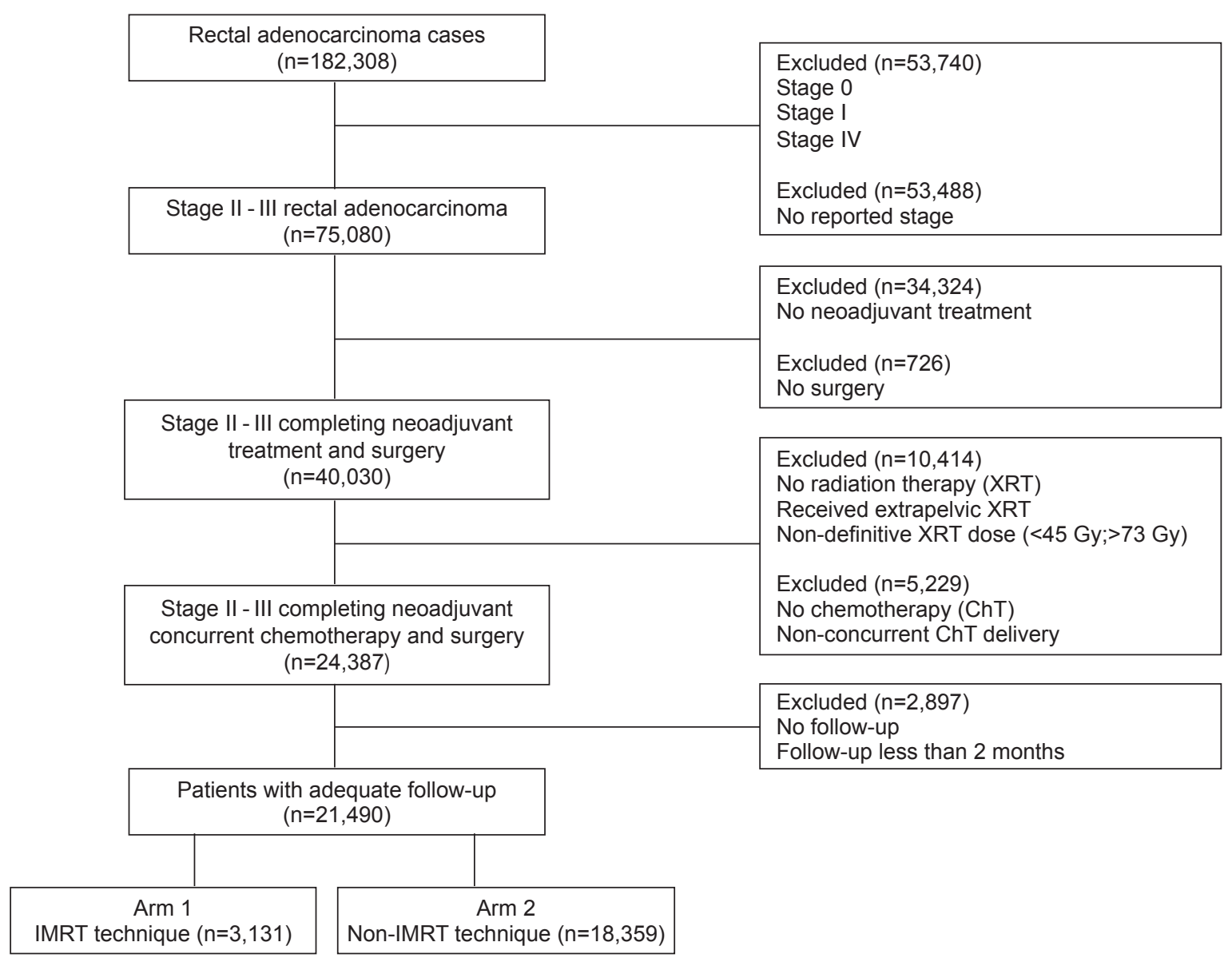

Fig. 1. CONSORT diagram: intensity-modulated radiation therapy (IMRT) versus non-IMRT in locally advanced rectal cancer.

\section{Results}

Using the criteria detailed above we identified 21,490 patients with stage 2-3 rectal cancer treated neoadjuvantly with chemoradiation. See Table 1 for full patient details. Of the entire group, 3,131 were treated using an IMRT technique. IMRT use increased over time, rate being 1\% in 2004 and 22\% by 2014 (Fig. 2). Patients with a higher comorbidity score, lower education level, those treated at an academic facility, and had higher $\mathrm{N}$ stage were more likely to be treated with IMRT (Table 2). The median radiation dose was 50.4 Gy (range, 45 to $73.8 \mathrm{~Gy}$ ) in 28 fractions. The median time to radiation from diagnosis was 33 days (interquartile range, 24 to 43 days). The median time to chemotherapy from diagnosis was 32 days (interquartile range, 23 to 43 days). The median follow-up for all patients was 49 months (range, 2 to 156 months). Median follow-up for patients receiving IMRT was 39 months (range, 3 to 151 months). Median follow-up for patients treated with 3D-CRT was 51 months (range, 2 to 155 months). Median

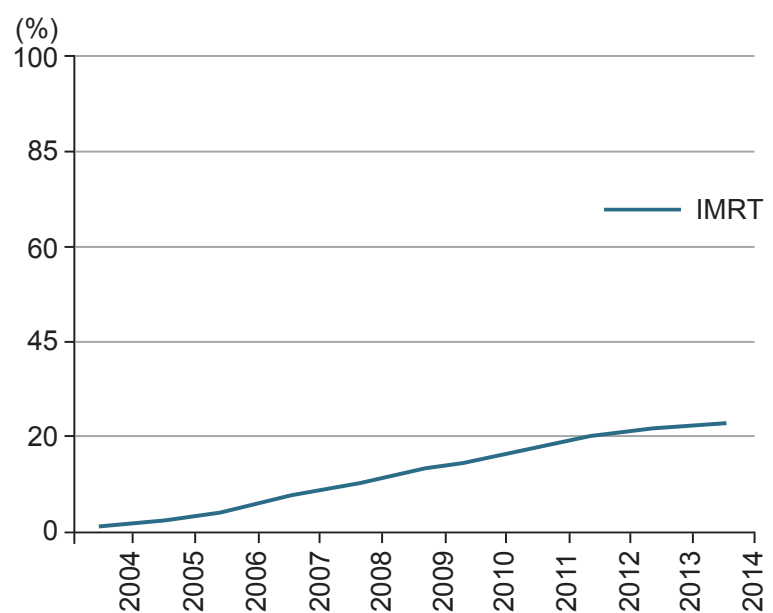

Fig. 2. Trends in intensity-modulated radiation therapy (IMRT) use over time. This figure shows a $<1 \%$ rate of IMRT use in 2004, and utilization reaching $>20 \%$ by 2014 . 
Table 1. Patient demographics and clinical characteristics at baseline $(n=21,490)$

\begin{tabular}{|c|c|}
\hline Characteristic & No. $(\%)$ \\
\hline \multicolumn{2}{|l|}{ Sex } \\
\hline Male & $13,467(63)$ \\
\hline Female & $8,024(37)$ \\
\hline \multicolumn{2}{|l|}{ Race } \\
\hline Caucasian & $18,742(87)$ \\
\hline African-American & $1,613(8)$ \\
\hline Other & $1,135(5)$ \\
\hline \multicolumn{2}{|l|}{ Comorbidity score } \\
\hline 0 & $17,063(79)$ \\
\hline 1 & $3,581(17)$ \\
\hline$\geq 2$ & $846(4)$ \\
\hline \multicolumn{2}{|l|}{ Insurance } \\
\hline Not insured & $1,019(5)$ \\
\hline Private payer & $11,151(52)$ \\
\hline Government & $9,069(42)$ \\
\hline Unrecorded & $251(1)$ \\
\hline \multicolumn{2}{|l|}{ Education (\%) } \\
\hline$\geq 29$ & $3,304(15)$ \\
\hline $20-28.9$ & $5,635(26)$ \\
\hline $14-19.9$ & $7,216(34)$ \\
\hline$<14$ & $5,198(24)$ \\
\hline Unrecorded & $137(1)$ \\
\hline \multicolumn{2}{|l|}{ Treatment facility type } \\
\hline Community cancer program & $1,725(8)$ \\
\hline Comprehensive community cancer program & $9,152(43)$ \\
\hline Academic/research program & $9,588(45)$ \\
\hline Unrecorded & $1,025(4)$ \\
\hline \multicolumn{2}{|l|}{ Treatment facility location } \\
\hline Metro & $16,775(78)$ \\
\hline Urban & $3,645(17)$ \\
\hline Rural & $551(3)$ \\
\hline Unrecorded & $519(2)$ \\
\hline \multicolumn{2}{|l|}{ Income (USD) } \\
\hline$<30,000$ & $3,573(17)$ \\
\hline $30,000-35,000$ & $5,286(24)$ \\
\hline $35,000-45,999$ & $5,954(27)$ \\
\hline$>46,000$ & $6,524(30)$ \\
\hline Unrecorded & $153(2)$ \\
\hline \multicolumn{2}{|l|}{ Distance to treatment facility (miles) } \\
\hline$\leq 11$ & $10,798(51)$ \\
\hline$>11$ & $10,692(49)$ \\
\hline \multicolumn{2}{|l|}{ Age distribution (yr) } \\
\hline$\leq 60$ & $10,281(49)$ \\
\hline$>60$ & $11,209(52)$ \\
\hline \multicolumn{2}{|l|}{ Year of diagnosis } \\
\hline 2004-2006 & $3,411(16)$ \\
\hline 2007-2009 & $5,280(25)$ \\
\hline 2010-2012 & $7,153(33)$ \\
\hline $2013-2015$ & $5,646(26)$ \\
\hline
\end{tabular}

\begin{tabular}{lc}
\hline T stage & \\
T1 & $131(1)$ \\
T2 & $1,007(5)$ \\
T3 & $18,348(87)$ \\
T4 & $1,635(7)$ \\
N Stage & \\
N0 & $9,827(47)$ \\
N1 & $9,539(45)$ \\
N2 & $1,611(8)$ \\
Grade & \\
Well differentiated & $1,486(7)$ \\
Moderately differentiated & $14,652(68)$ \\
Poorly differentiated & $2,537(12)$ \\
Not recorded & $2,815(13)$ \\
Radiation technique & \\
Non-IMRT & $18,359(85)$ \\
IMRT & $3,131(15)$
\end{tabular}

IMRT, intensity-modulated radiation therapy.

overall survival was 138 months, with a 5-year survival of 75\%. On univariable analysis, median overall survival was 109 months with IMRT compared to 139 months with 3D-CRT ( $p$ $=0.0004$ ). Five-year overall survival was almost identical, 75\% versus $74.6 \%$ in favor of 3D-CRT.

On multivariable analysis increasing age, male gender, higher comorbidity score, higher grade, IMRT use, government insurance, African-American race, and increasing stage corresponded to worse overall survival (Table 3). As described in the methods, a logistic regression was used to generate a propensity score and included age, facility type, educational level, income, $\mathrm{N}$ stage, T stage, and year of treatment. Multivariable analysis with propensity score included was then run to determine predictors of outcome (excluding those factors used to generate propensity score). This multivariable analysis confirmed higher comorbidity score, high grade, government insurance, rural location, African-American race, male gender and IMRT use as predictive of worse overall survival (Table 4). In addition, NCDB does contain pathologic staging information. After completion of neoadjuvant therapy $21 \%$ of patients in the IMRT group and $28 \%$ in the non-IMRT group had a pathologic complete response.

\section{Discussion and Conclusion}

Rectal cancer remains a commonly diagnosed malignancy of the lower gastrointestinal tract. Upfront chemoradiation therapy is generally the preferred approach for patients with node positive or T3 disease based on multiple well-designed 
Table 2. Comparative use of conventional radiation therapy (XRT) versus IMRT by baseline characteristics in patients receiving treatment for rectal cancer

\begin{tabular}{|c|c|c|c|c|c|}
\hline Characteristic & $\begin{array}{l}\text { Conventional XRT } \\
\quad(n=18,359)\end{array}$ & $\begin{array}{c}\text { IMRT } \\
(n=3,131)\end{array}$ & $\mathrm{OR}$ & $95 \% \mathrm{Cl}$ & $p$-value \\
\hline \multicolumn{6}{|l|}{ Sex } \\
\hline Male & $11,507(63)$ & $1,960(63)$ & 1 & Ref & \\
\hline Female & $6,852(37)$ & $1,171(37)$ & 1.00 & $0.93-1.09$ & 0.93 \\
\hline \multicolumn{6}{|l|}{ Race } \\
\hline Caucasian & $15,990(87)$ & $2,752(88)$ & 1 & Ref & \\
\hline African-American & 1,389 (8) & $224(7)$ & 0.94 & $0.81-1.09$ & 0.39 \\
\hline Other & $980(5)$ & $155(5)$ & 0.92 & $0.77-1.09$ & 0.34 \\
\hline \multicolumn{6}{|l|}{ Comorbidity score } \\
\hline 0 & $14,615(80)$ & $2,448(78)$ & 1 & Ref & \\
\hline 1 & $3,048(17)$ & 533 (17) & 1.04 & $0.94-1.16$ & 0.41 \\
\hline$\geq 2$ & 696 (3) & $150(5)$ & 1.29 & $1.07-1.54$ & $0.0065^{*}$ \\
\hline \multicolumn{6}{|l|}{ Age (yr) } \\
\hline$\leq 60$ & $9,609(52)$ & $1,600(51)$ & 1 & Ref & \\
\hline$>60$ & $8,750(48)$ & $1,531(49)$ & 1.05 & $0.97-1.13$ & 0.2 \\
\hline \multicolumn{6}{|l|}{ Insurance } \\
\hline None & $857(5)$ & $162(5)$ & 1 & Ref & \\
\hline Private payer & $9,569(53)$ & $1,582(51)$ & 0.87 & $0.73-1.04$ & 0.13 \\
\hline Government & $7,718(42)$ & $1,351(44)$ & 0.92 & $0.77-1.11$ & 0.40 \\
\hline \multicolumn{6}{|l|}{ Education (\%) } \\
\hline$\geq 29$ & $2,890(16)$ & $414(13)$ & 1 & Ref & \\
\hline $20-28.9$ & 4,837 (27) & $798(26)$ & 1.15 & $1.01-1.31$ & $0.0298^{*}$ \\
\hline $14-19.9$ & 6,089 (33) & $1,127(36)$ & 1.29 & $1.14-1.46$ & $<0.0001^{*}$ \\
\hline$<14$ & $4,421(24)$ & $777(25)$ & 1.23 & $1.08-1.39$ & $0.0018^{*}$ \\
\hline \multicolumn{6}{|l|}{ Facility type } \\
\hline Community cancer program & $1,506(9)$ & $219(7)$ & 1 & Ref & \\
\hline Comprehensive cancer program & $7,788(45)$ & $1,364(46)$ & 1.2 & $1.03-1.40$ & $0.0172^{*}$ \\
\hline Academic/research program & $8,185(46)$ & $1,403(47)$ & 1.18 & $1.01-1.37$ & $0.0347^{*}$ \\
\hline \multicolumn{6}{|l|}{ Facility location } \\
\hline Metro & $14.302(80)$ & $2,473(81)$ & 1 & Ref & \\
\hline Urban & $3,127(17)$ & $518(17)$ & 0.96 & $0.86-1.06$ & 0.41 \\
\hline Rural & $484(3)$ & $67(2)$ & 0.80 & $0.62-1.04$ & 0.09 \\
\hline \multicolumn{6}{|l|}{ Income (USD) } \\
\hline$<30,000$ & $3,101(17)$ & $472(15)$ & 1 & Ref & \\
\hline $30,000-35,000$ & $4,493(25)$ & $793(25)$ & 1.16 & $1.03-1.31$ & $0.0181^{*}$ \\
\hline $35,000-45,999$ & $5,037(28)$ & $917(29)$ & 1.20 & $1.06-1.35$ & $0.0034^{*}$ \\
\hline$>46,000$ & $5,592(30)$ & $932(31)$ & 1.10 & $0.97-1.23$ & 0.14 \\
\hline \multicolumn{6}{|l|}{ T stage } \\
\hline T1 & $110(1)$ & $21(1)$ & 1 & Ref & \\
\hline $\mathrm{T} 2$ & $852(5)$ & $155(5)$ & 0.95 & $0.58-1.57$ & 0.85 \\
\hline T3 & $15,747(87)$ & $2,601(84)$ & 0.87 & $0.54-1.38$ & 0.54 \\
\hline $\mathrm{T} 4$ & 1,327 (7) & $308(10)$ & 1.22 & $0.75-1.97$ & 0.43 \\
\hline \multicolumn{6}{|l|}{ N stage } \\
\hline No & $8,494(47)$ & $1,333(43)$ & 1 & Ref & \\
\hline N1 & $8,079(45)$ & $1,460(47)$ & 1.15 & $1.06-1.25$ & $0.0006^{*}$ \\
\hline N2 & $1,321(8)$ & $290(10)$ & 1.40 & $1.22-1.61$ & $<0.0001^{*}$ \\
\hline \multicolumn{6}{|l|}{ Distance to facility (miles) } \\
\hline$\leq 11$ & $9,098(50)$ & $1,594(49)$ & 1 & Ref & \\
\hline$>11$ & $9,261(50)$ & $1,537(51)$ & 0.94 & $0.88-1.02$ & 0.16 \\
\hline
\end{tabular}

Continued on the next page. 
Table 2. Continued

\begin{tabular}{|c|c|c|c|c|c|}
\hline Characteristic & $\begin{array}{l}\text { Conventional XRT } \\
\quad(n=18,359)\end{array}$ & $\begin{array}{c}\text { IMRT } \\
(n=3,131)\end{array}$ & $\mathrm{OR}$ & $95 \% \mathrm{Cl}$ & $p$-value \\
\hline \multicolumn{6}{|l|}{ Grade } \\
\hline Well differentiated & $1,278(8)$ & $208(8)$ & 1 & Ref & \\
\hline Moderately differentiated & $12,533(78)$ & $2,119(79)$ & 1.04 & $0.89-1.21$ & 0.63 \\
\hline Poorly differentiated & $2,178(14)$ & 359 (13) & 1.01 & $0.84-1.22$ & 0.89 \\
\hline \multicolumn{6}{|l|}{ Year of diagnosis } \\
\hline 2004-2006 & $3,315(18)$ & $96(3)$ & 1 & Ref & \\
\hline 2007-2009 & $4,743(26)$ & 537 (17) & 3.91 & $3.13-4.88$ & $<0.0001^{*}$ \\
\hline 2010-2012 & $5,893(32)$ & $1,260(40)$ & 7.38 & $5.97-9.13$ & $<0.0001^{*}$ \\
\hline $2013-2015$ & $4,408(24)$ & $1,238(40)$ & 9.7 & 7.84-11.99 & $<0.0001^{*}$ \\
\hline
\end{tabular}

Values are presented as number (\%).

IMRT, intensity-modulated radiation therapy; $\mathrm{OR}$, odds ratio; $\mathrm{Cl}$, confidence interval.

${ }^{*} p<0.05$.

randomized control trials, showing less toxicity, better chance at sphincter preservation, and slight improvement in local control $[2,3]$. In terms of radiation therapy, technology has evolved over the past 30 years, transitioning (going) from 2-dimensional $\mathrm{X}$-ray based planning, to now utilizing advanced imaging such as CT, MRI, and PET-CT to more precisely deliver radiation based on each patient's individual anatomy and tumor characteristics. IMRT allows for a more conformal dose distribution, at times allowing for dose escalation, and almost always allowing for sparing of surrounding normal structures with the goal of reduction of toxicity [5].

At the current time, IMRT is the standard of care for another pelvic malignancy, anal cancer, based on the groundbreaking results of RTOG 0529 which explored the use of IMRT in reducing treatment-related toxicity [7]. Results of that study showed that IMRT use was significantly associated with reduced rates of grade 2 hematologic and grade 3 dermatologic and gastrointestinal toxicity. A secondary analysis was later published confirming that increasing small bowel volumetric dose correlated with increasing toxicity [18]. As expected, a recent NCDB analysis showed significant increase in IMRT use over time for anal cancer [19]. It is our opinion that these results can reasonably be extrapolated to rectal cancer. For example, most experts in the field encourage treatment of the inguinal nodes for low lying rectal cancers which may drain to that location [8]. In addition, for more classic mid to upper rectal cancers, the main organ at risk which drives short and long term toxicity is the small bowel. An early prospective series evaluated IMRT and 3D-CRT plans in over 20 patients, clearly showing reduced dose to small bowel and bone marrow with IMRT [9]. Direct comparison of toxicity was not possible since each patient served as their (it) own control. However, compared to historical rates the grade 3 toxicity was reduced. A similar study was conducted at MD Anderson, where 10 patients with rectal cancer were treated using IMRT, but also had 3D-CRT plans generated for comparison based on bony anatomy [10]. As expected, the IMRT plans had significantly reduced dose to small bowel, bladder, bone marrow and femoral heads. Lastly, the group from Harvard conducted a retrospective review on close to 50 patients treated with either 3D-CRT (58\%) or IMRT (42\%) in the preoperative setting [11]. With IMRT, the rate of grade 2 or higher gastrointestinal toxicity was significantly reduced (60\% down to $30 \%$ ). In addition, treatment duration was less with IMRT and pathologic complete response (pCR) rate was 21\% with IMRT compared to 16\% in the 3D cohort.

$A$ recent $N C D B$ analysis confirms that neoadjuvant chemoradiation has increased in use for the treatment of rectal cancer, without specifically commenting on the radiation technique [4]. A study just published this year examined the use of IMRT in close to 1,000 rectal cancer patients treated across the National Comprehensive Cancer Network (NCCN) centers between 2005 and 2011 [20]. IMRT use began at $<13 \%$ and rose to $>30 \%$ by 2010 within those centers. When reviewing these results, one must keep in mind that the NCDB also contains data from community cancer centers. Our results did show an increased likelihood of receiving IMRT if treated at an academic center (Table 2). The results of our analysis confirmed increasing use of IMRT in rectal cancer peaking at $>20 \%$ in 2014, beginning at $<1 \%$ in 2004. These numbers likely differ from the NCCN group study based on inclusion of community centers and overall larger sample size. Compared 
Table 3. Multivariable Cox proportional hazards models for overall survival in patients receiving treatment for rectal adenocarcinoma (Cox model without propensity score)

\begin{tabular}{|c|c|c|}
\hline Significant characteristic & $\begin{array}{l}\text { Hazard of death } \\
\qquad(95 \% \mathrm{CI})\end{array}$ & p-value \\
\hline \multicolumn{3}{|l|}{ Age (yr) } \\
\hline$\leq 60$ & Ref & \\
\hline$>60$ & $1.46(1.37-1.56)$ & $<0.0001$ \\
\hline \multicolumn{3}{|l|}{ Sex } \\
\hline Male & Ref & \\
\hline Female & $0.82(0.78-0.87)$ & $<0.0001$ \\
\hline \multicolumn{3}{|l|}{ Distance (miles) } \\
\hline$\leq 11$ & Ref & \\
\hline$>11$ & $0.94(0.89-1.00)$ & 0.0351 \\
\hline \multicolumn{3}{|l|}{ Comorbidity score } \\
\hline 0 & Ref & \\
\hline 1 & $1.27(1.19-1.36)$ & $<0.0001$ \\
\hline$\geq 2$ & $1.90(1.70-2.13)$ & $<0.0001$ \\
\hline \multicolumn{3}{|l|}{ Radiation technique } \\
\hline Non-IMRT & Ref & \\
\hline IMRT & $1.12(1.04-1.22)$ & 0.0042 \\
\hline \multicolumn{3}{|l|}{ Insurance } \\
\hline None & Ref & \\
\hline Private & $0.76(0.68-0.86)$ & $<0.0001$ \\
\hline Government & $1.14(1.01-1.28)$ & 0.0343 \\
\hline \multicolumn{3}{|l|}{ Grade } \\
\hline Well differentiated & Ref & \\
\hline Moderately differentiated & $0.99(0.89-1.11)$ & 0.9 \\
\hline Poorly differentiated & $1.68(1.57-1.80)$ & $<0.0001$ \\
\hline \multicolumn{3}{|l|}{ Facility type } \\
\hline Community cancer program & Ref & \\
\hline Comprehensive cancer program & $0.93(0.85-1.03)$ & 0.16 \\
\hline Academic/research program & $0.91(0.86-0.96)$ & 0.001 \\
\hline \multicolumn{3}{|l|}{ Income (USD) } \\
\hline$<30,000$ & Ref & \\
\hline $30,000-35,000$ & $0.95(0.87-1.04)$ & 0.28 \\
\hline $35,000-45.999$ & $0.93(0.87-0.99)$ & 0.0273 \\
\hline$>46,000$ & $0.85(0.79-0.92)$ & 0.0001 \\
\hline \multicolumn{3}{|l|}{ Education (\%) } \\
\hline$\geq 29$ & Ref & \\
\hline $20-28.9$ & $0.99(0.91-1.09)$ & 0.93 \\
\hline $14-19.9$ & $0.99(0.90-1.08)$ & 0.77 \\
\hline$<14$ & $0.91(0.84-0.99)$ & 0.02 \\
\hline \multicolumn{3}{|l|}{ N stage } \\
\hline NO & Ref & \\
\hline N1 & $1.05(1.00-1.11)$ & 0.07 \\
\hline N2 & $1.36(1.22-1.50)$ & $<0.0001$ \\
\hline \multicolumn{3}{|l|}{ T stage } \\
\hline $\mathrm{T} 1$ & Ref & \\
\hline $\mathrm{T} 2$ & $0.85(0.74-0.98)$ & 0.0223 \\
\hline T3 & $0.93(0.30-2.90)$ & 0.91 \\
\hline T4 & $1.70(1.56-1.85)$ & $<0.0001$ \\
\hline
\end{tabular}

\begin{tabular}{lcc}
\hline Race & Ref & \\
Caucasian & $1.13(1.02-1.25)$ & 0.016 \\
African-American & $0.98(0.86-1.11)$ & 0.72 \\
Other & Ref & \\
Year of diagnosis & $0.96(0,90-1.03)$ & 0.32 \\
2004-2006 & $0.96(0.89-1.03)$ & 0.26 \\
2007-2009 & $0.88(0.80-0.97)$ & 0.0079 \\
$2010-2012$ & & \\
$2013-2015$ & & \\
\hline
\end{tabular}

IMRT, intensity-modulated radiation therapy; $\mathrm{Cl}$, confidence interval.

Table 4. Multivariable Cox proportional hazards models for overall survival in patients receiving treatment for rectal adenocarcinoma incorporating propensity score (Cox model with propensity score)

\begin{tabular}{|c|c|c|}
\hline Significant characteristic & $\begin{array}{l}\text { Hazard of death } \\
\qquad(95 \% \mathrm{Cl})\end{array}$ & $p$-value \\
\hline \multicolumn{3}{|l|}{ Sex } \\
\hline Male & Ref & \\
\hline Female & $0.83(0.79-0.88)$ & $<0.0001$ \\
\hline \multicolumn{3}{|l|}{ Distance (miles) } \\
\hline$\leq 11$ & Ref & \\
\hline$>11$ & $0.93(0.87-0.98)$ & 0.008 \\
\hline \multicolumn{3}{|l|}{ Comorbidity score } \\
\hline 0 & Ref & \\
\hline 1 & $1.30(1.22-1.39)$ & $<0.0001$ \\
\hline$\geq 2$ & $1.91(1.71-2.13)$ & $<0.0001$ \\
\hline \multicolumn{3}{|l|}{ Radiation technique } \\
\hline Non-IMRT & Ref & \\
\hline IMRT & $1.13(1.05-1.22)$ & 0.0022 \\
\hline \multicolumn{3}{|l|}{ Insurance } \\
\hline None & Ref & \\
\hline Private & $0.71(0.63-0.79)$ & $<0.0001$ \\
\hline Government & $1.32(1.17-1.47)$ & $<0.0001$ \\
\hline \multicolumn{3}{|l|}{ Grade } \\
\hline Well differentiated & Ref & \\
\hline Moderately differentiated & $1.01(0.90-1.12)$ & 0.92 \\
\hline Poorly differentiated & $1.70(1.59-1.82)$ & $<0.0001$ \\
\hline \multicolumn{3}{|l|}{ Facility location } \\
\hline Metropolitan & Ref & \\
\hline Urban & $1.12(1.04-1.21)$ & 0.0031 \\
\hline Rural & $1.18(1.00-1.39)$ & 0.049 \\
\hline \multicolumn{3}{|l|}{ Race } \\
\hline White & Ref & \\
\hline African-American & $1.15(1.04-1.26)$ & 0.0056 \\
\hline Other & $0.91(0.80-1.04)$ & 0.15 \\
\hline
\end{tabular}


to anal cancer, IMRT use is still relatively low in rectal cancer, with a recent NCDB analysis showing rates eclipsing 90\% [19].

Of note, and as an aside, IMRT patients did worse in our analysis in terms of overall survival. In that vein, a similar analysis published last year from Duke using the NCDB reported that patients with rectal cancer treated with IMRT had a higher risk of positive margins and failure to preserve sphincter function [21]. We must keep in mind that the goal of our study, and what the NCDB is most useful for, is examining trends and associations in treatment and outcomes. The decreased survival in the IMRT group is quite easily explained by their higher comorbid scores and higher $\mathrm{N}$ stage. In addition, we do not know if IMRT patients had more aggressive low lying cancers or otherwise advanced disease. One could reasonably postulate that is likely the case given the lower pCR rate in the IMRT patients. Furthermore, one could reason that since the patients treated with IMRT more often had a higher comorbid score, that perhaps IMRT was used to potentially offer a non-surgical option, or a lesser surgery, which may have had less likelihood of cure. Unfortunately, type of surgery (local excision compared to LAR/TME) is not clearly documented in the NCDB. The limitations of this study are those intrinsic to the dataset and NCDB, including the retrospective nature of collection and analysis, as well as, the associated selection bias. In addition, NCDB lacks important data on toxicity, local failure, chemotherapeutic agent(s) and number of treatment cycles completed, all of which play an important role in determining outcome for rectal cancer. Salvage therapy is also not recorded in the NCDB, which is an important player in long term rectal cancer outcomes.

In conclusion, the results of this NCDB analysis show a steady uptick in the use of IMRT for rectal cancer in the preoperative setting across the years 2004-2015, particularly for patients with higher disease burden. This phenomenon is not surprising given existing data supporting lower toxicity. A continued increase in IMRT use is expected.

\section{Conflict of Interest}

No potential conflict of interest relevant to this article was reported.

\section{References}

1. Siegel RL, Miller KD, Jemal A. Cancer statistics, 2018. CA Cancer J Clin 2018;68(1):7-30.

2. Sauer $R$, Becker $H_{1}$ Hohenberger $W_{1}$ et al. Preoperative versus postoperative chemoradiotherapy for rectal cancer. N Engl J Med 2004;351:1731-40.

3. Sauer R, Liersch T, Merkel $S$, et al. Preoperative versus postoperative chemoradiotherapy for locally advanced rectal cancer: results of the German CAO/ARO/AIO-94 randomized phase III trial after a median follow-up of 11 years. J Clin Oncol 2012;30:1926-33.

4. Sineshaw HM, Jemal A, Thomas CR Jr, Mitin T. Changes in treatment patterns for patients with locally advanced rectal cancer in the United States over the past decade: an analysis from the National Cancer Data Base. Cancer 2016;122:19962003.

5. Intensity Modulated Radiation Therapy Collaborative Working Group. Intensity-modulated radiotherapy: current status and issues of interest. Int J Radiat Oncol Biol Phys. 2001;51:880914.

6. Fredman ET, Abdel-Wahab M, Kumar AMS. Influence of radiation treatment technique on outcome and toxicity in anal cancer. J Radiat Oncol 2017;6:413-21.

7. Kachnic LA, Winter K, Myerson RJ, et al. RTOG 0529: a phase 2 evaluation of dose-painted intensity modulated radiation therapy in combination with 5 -fluorouracil and mitomycin- $\mathrm{C}$ for the reduction of acute morbidity in carcinoma of the anal canal. Int J Radiat Oncol Biol Phys 2013;86:27-33.

8. Taylor N, Crane C, Skibber J, et al. Elective groin irradiation is not indicated for patients with adenocarcinoma of the rectum extending to the anal canal. Int J Radiat Oncol Biol Phys 2001;51:741-7.

9. Patel S, Vuong T, Ballivy O, Portelance L, Parker W, Patrocinio H. Phase II trial of pelvic intensity-modulated radiotherapy (IMRT) with concurrent chemotherapy for patients with rectal cancer. Int J Radiat Oncol Biol Phys 2014;60:S424-S425.

10. Mok $\mathrm{H}$, Crane $\mathrm{CH}_{\text {, Palmer }} \mathrm{MB}$, et al. Intensity modulated radiation therapy (IMRT): differences in target volumes and improvement in clinically relevant doses to small bowel in rectal carcinoma. Radiat Oncol 2011;6:63.

11. Parekh A, Truong MT, Pashtan I, et al. Acute gastrointestinal toxicity and tumor response with preoperative intensity modulated radiation therapy for rectal cancer. Gastrointest Cancer Res 2013;6:137-43.

12. Hasan S, Renz P, Turrisi A, Colonias A, Finley G, Wegner RE. Dose escalation and associated predictors of survival with consolidative thoracic radiotherapy in extensive stage small cell lung cancer (SCLC): A National Cancer Database (NCDB) propensity-matched analysis. Lung Cancer 2018;124:283-90.

13. Hasan $S$, Renz $P$, Wegner RE, et al. Microsatellite instability (MSI) as an independent predictor of pathologic complete 
response $(P C R)$ in locally advanced rectal cancer: a National Cancer Database (NCDB) Analysis. Ann Surg 2018 Sep 13 [Epub]. http://doi.org/10.1097/SLA.0000000000003051.

14. Deyo RA, Cherkin DC, Ciol MA. Adapting a clinical comorbidity index for use with ICD-9-CM administrative databases. J Clin Epidemiol 1992;45:613-9.

15. Kaplan EL, Meier P. Nonparametric estimation from incomplete observations. J Am Stat Assoc 1958;53:457-81.

16. Cox DR. Regression models and life-tables. J R Stat Soc Series B Methodol 1972;34:187-220.

17. D'Agostino RB Jr. Propensity score methods for bias reduction in the comparison of a treatment to a non-randomized control group. Stat Med 1998;17:2265-81.

18. Olsen JR, Moughan J, Myerson R, et al. Predictors of radiation therapy-related gastrointestinal toxicity from anal cancer dose-painted intensity modulated radiation therapy: secondary analysis of NRG Oncology RTOG 0529. Int J Radiat Oncol Biol Phys 2017;98:400-8.

19. Haque W, Verma $V$, Butler EB, Teh BS. Utilization of intensity modulated radiation therapy for anal cancer in the United States. J Gastrointest Oncol 2018;9:466-77.

20. Reyngold M, Niland J, Ter Veer A, et al. Trends in intensity modulated radiation therapy use for locally advanced rectal cancer at National Comprehensive Cancer Network centers. Adv Radiat Oncol 2017;3:34-41.

21. Sun Z, Adam MA, Kim J, Czito B, Mantyh C, Migaly J. Intensity-modulated radiation therapy is not associated with perioperative or survival benefit over 3D-conformal radiotherapy for rectal cancer. J Gastrointest Surg 2017;21:106-11. 